\title{
Seasonal consumption of salad vegetables and fresh fruit in relation to the development of cardiovascular disease and cancer
}

\author{
Brian D Cox ${ }^{1, *}$, Margaret J Whichelow ${ }^{1}$ and A Toby Prevost ${ }^{2}$ \\ 'Health and Lifestyle Survey, Department of Community Medicine, Institute of Public Health, Robinson Way, \\ Cambridge CB2 2SR, UK: ${ }^{2}$ Centre for Applied Medical Statistics, Department of Community Medicine, Institute of \\ Public Health, Robinson Way, Cambridge CB2 2SR, UK
}

Submitted 26 February 1999: Accepted 7 July 1999

\begin{abstract}
Objective: To investigate the protective association between seasonality of consumption of fresh fruit or salad vegetables and cancer and cardiovascular disease (CVD) development.

Design and setting: Face-to-face interviews, including a food frequency questionnaire, were conducted on 1489 men and 1900 women, aged 35-75 years, who were respondents in the British Health and Lifestyle Survey 1984/85 (HALS1). CVD and cancer morbidity and mortality were determined from the 1991/92 British Health and Lifestyle Survey (HALS2) and by NHS Register 'flagging'.

Results: Risk was assessed by odds ratio (OR) for trend per frequency category. In men, frequent winter salad vegetable consumption was more closely protective than that in summer for cancer (winter $\mathrm{OR}=0.79$ [0.62-0.99], $P=0.045$, summer $\mathrm{OR}=0.83$ [0.69-1.01], NS) and CVD (winter OR $=0.85$ [0.72-1.00], $P=0.049$, summer OR $=0.95$ [0.82-1.10], NS). Fresh fruit consumption showed no significant protection. In women, frequent salad vegetable consumption at any season was significantly protective of CVD (winter OR $=0.76$ [0.65-0.89], $P<0.001$, summer OR $=0.76$ [0.650.89], $P<0.001$ ), although not of cancer. Frequent fresh fruit consumption in women was significantly protective of CVD (winter $\mathrm{OR}=0.84$ [0.74-0.94], $P=0.004$, summer $\mathrm{OR}=0.85[0.74-0.97], P=0.014)$ but not quite significant, and only in winter, for cancer (winter $\mathrm{OR}=0.87$ [0.76-1.00], $P=0.052$, summer $\mathrm{OR}=0.88$ [0.75-1.02], $P=$ 0.097). Maintenance of salad vegetable consumption from summer to winter, to within one frequency category, was associated with further protection for cancer in men $(P=0.050)$ and CVD in women $(P=0.024)$.

Conclusions: Diets high in fresh fruit and salad vegetables appear protective against cancer and CVD. It is important to take into account the seasonality of consumption in estimating and establishing significance of risk.
\end{abstract}

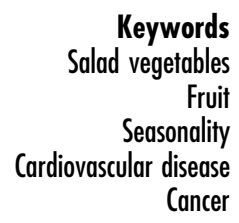

Many ecological studies have shown in countries and regions of low fruit and/or vegetable consumption that there are higher rates of CVD than where the intakes of fruit and/or vegetables are high ${ }^{1}$. These findings have led to the hypothesis that the 'Mediterranean diet' (high in fruit and vegetables and low in animal fats) is protective against CVD. However case-control and prospective cohort studies, also reviewed by Ness and Powles ${ }^{1}$, have not shown such consistent results.

Whilst the majority of the 217 case-control and cohort studies reported by the World Cancer Research Fund ${ }^{2}$ found significant inverse relationships between cancer at various sites, particularly the mouth and pharynx, oesophagus, lung, stomach and bowel, and fruit (percentage of studies: 64\% for all fruit, 66\% for citrus fruit) and vegetables (percentage of studies: $87 \%$ for raw vegetables, $81 \%$ for carrots, $80 \%$ for all vegetables, $77 \%$ for alliums, $77 \%$ for green vegetables, $71 \%$ for tomatoes, $69 \%$ for cruciferous vegetables), some studies showed no association and a few showed positive relationships. Foods for which the lowest proportion of studies found significant positive relationships were raw vegetables (4\%) and fruit (9\%).

A possible or partial explanation for these inconsistencies is that the variation in consumption of these foods across the seasons has not been taken into account. Data from the National Food Survey ${ }^{3}$ in Great Britain reveals that salad vegetable consumption as assessed from leafy salads, cucumbers and tomatoes, was almost three times as high during the period April to September as from October to March, and total fruit consumption was $12 \%$ higher. The proportion of respondents frequently consuming salad vegetables and fruit was also found to be higher in summer than winter in respondents in HALS $1^{4}$ and the follow-up survey of 1991/92 (HALS2) ${ }^{5}$. Powles et al. ${ }^{6}$ have further postulated that the availability of fresh 
food (i.e. fruit and vegetables) is a key to low vascular mortality. Cross-sectional studies based on the HALS1 survey population showed that all-year-round (summer and winter), but not summer-only, fruit consumption was associated with good lung function ${ }^{7}$ in light and nonsmokers, having adjusted for sex, age, socioeconomic group and region of residence, and also with 'good' or 'excellent' self-reported health in men and women, having adjusted for age, smoking habit and socioeconomic group ${ }^{8}$.

Preliminary reports based on findings from HALS $1^{4}$ and HALS $2^{5}$ have found a protective effect of all-year-round fruit consumption on $\mathrm{CVD}^{9}$ and, on cancer, of winter salad consumption for men and winter fruit consumption for women, adjusted for age and smoking habit ${ }^{10}$.

Thus there is evidence of the importance of seasonality in the role of fresh fruit and salad vegetables in the maintenance of health. The present study was undertaken to examine this in depth in a longitudinal study of a random sample of British adults in relation to the development of CVD and cancer morbidity and mortality over 7 years.

\section{Methods}

The subjects in this study were 1489 men and 1900 women aged 35-75 years, who were participants in HALS $1^{4}$ and who were either interviewed again in the follow-up survey 7 years later (HALS2) ${ }^{5}$ or had died from CVD or cancer by then. For the cancer analysis, there were 1442 men and 1875 women - none of whom had a diagnosis of cancer at HALS1 or had died of diseases other than cancer before HALS2. For the investigation of the development of CVD there were 1422 men and 1826 women, all of whom were free of CVD at HALS1 and who did not die of any other disease before HALS2. For the analysis of the development of CVD and/or cancer there were 1489 men and 1900 women without either disease at HALS1.

The sampling procedures and execution of the first Health and Lifestyle Survey which took place in 1984/85 are described in detail elsewhere ${ }^{11}$. From households selected at random in 198 representative constituencies in England, Scotland and Wales, 9003 adults (a response rate of $77.5 \%$ ) were interviewed. The age structure of the samples for both men and women compared well with that of the 1981 census. An interviewer visited the respondents at home and administered a questionnaire, which took approximately 1 hour to complete, covering attitudes to, and knowledge about, health, self-reported health, eating habits, smoking, alcohol consumption and exercise activities, as well as demographic details. For 31 food items the frequency of consumption was recorded in six categories: 'Never', 'Less than once a week', 'Once or twice a week', 'Most days', 'Daily' and 'More than once a day $^{12}$. For seasonal foods such as fresh fruit and salad or raw vegetables, the respondents were asked about their consumption in summer and winter separately.

At HALS1 and HALS2 the respondents were asked if they had any long-standing illness or disability or if they had ever suffered from any of a list of diseases, including CVD and cancers, and if so whether they had been treated for the condition. A positive diagnosis was assumed if the condition reported had been treated. The survey respondents were 'flagged' with the NHS Central Register at the Office of National Statistics (ONS), so that dates and causes of death of respondents are notified to the Health and Lifestyle Survey team as they occur.

The presence of CVD at HALS1 and HALS2 was assumed if the responses, or medication used, indicated that the subject had had a myocardial infarction, heart by-pass operation, peripheral vascular disease, angina pectoris or stroke. Mortality from CVD was identified from ICD9 codes 390 to 459 on the death certificates. A diagnosis of cancer (all sites) was assumed if the responses, or medication used, so indicated. Mortality from cancer was identified from ICD9 codes 140 to 239 on the death certificates. The numbers of respondents developing cancer or CVD were too small to perform analysis on individual CVDs or cancer sites.

The respondents were classified as non-smokers (those who had never regularly smoked as much as one cigarette, pipe or cigar a day for 6 months), light smokers (current regular smokers who smoked cigars, pipes or up to 15 cigarettes a day), heavy smokers (those currently smoking over 15 cigarettes a day) and ex-smokers (those who used to smoke regularly).

Socioeconomic group for the head of the household was assessed according to the Registrar General's classification. Married and widowed women were classified by their husbands' occupations and single and divorced women by their own occupation. The eleven standard regions of Great Britain were condensed as northern (North, North West, Yorkshire/Humberside, West Midlands), southern (Greater London, South East, South West, East Anglia, East Midlands), Wales and Scotland.

\section{Statistical analyses}

Logistic regression analysis (SPSS) was used to estimate the risk of developing cancer, CVD and cancer and/or CVD (morbidity and/or mortality) over 7 years across the categories of frequency of food consumption: 'Never', 'Less than once a week', 'Once or twice a week', 'Most (3-6) days' and 'Daily' (including more than once a day). Odds ratios were estimated which contrasted with the 'Never' category as the reference category. Confidence intervals for these 'odds ratio contrasts' were not presented due to the widely differing sample sizes in the 'Never' category and other frequencies of consumption. Trend was tested using the values $1,2,3,4,5$ in place of the above-stated categories. The likelihood ratio test statistic 
was compared to a chi-square distribution with 1 degree of freedom in all significance tests for linear trend across the categories.

'Salad change' and 'fruit change' variables, that reflected seasonal change in consumption from summer to winter (with categories 'maintenance' and 'reduction') were derived for each respondent. 'Reduction' was defined as reporting winter consumption that was at least two frequency categories lower than that reported for summer. For example, those who were 'daily' summer consumers but who reduced their winter intake frequency to no more than 'once or twice a week' were in the 'reduction group', as were those who changed from 'Once or twice a week' in summer to 'Never' in winter. 'Maintenance' was defined as the converse. Those whose summer consumption was 'Less than once a week' or 'Never' did not contribute to the analysis of seasonal change as they were not eligible to reduce their consumption. The odds ratio (OR) for developing, for example, CVD that was associated with 'reduction' in salad consumption was obtained by adding 'salad change' to the logistic regression model having summer salad consumption as a categorical covariate.

The OR estimates obtained from all the models were adjusted for age in 5-year categories (to accommodate the skewed distribution of disease development), socioeconomic group in two categories (non-manual and manual) and smoking as a categorical covariate (non-smokers, light, heavy and ex-smokers). The likelihood ratio test statistic was compared to chi-square distributions in all significance tests. All 95\% confidence intervals for linear trends, and other log OR estimates, were calculated as parameters plus or minus 1.96 estimated standard errors.

\section{Results}

The numbers and proportions of men and women developing cancer, CVD and CVD and/or cancer in the 7 years between HALS1 and HALS2 are shown in Table 1. More men than women developed CVD, but the rates for cancer were more similar, although cancer mortality was higher amongst men than women.

Tables $2 \mathrm{a}$ and $\mathrm{b}$ compares the summer and winter frequency of consumption of fresh fruit and salad vegetables. Most subjects ate salad vegetables less frequently in winter than in summer, with (excluding those who never ate salads) only $21.2 \%$ of men and $23.6 \%$ of women consuming salad vegetables with the same frequency year round. In contrast, most men (60.0\%) and women (65.9\%), consumed fresh fruit with the same frequency summer and winter, and whilst $5.0 \%$ of men and $2.8 \%$ of women never ate fresh fruit, the rest reduced their consumption in winter. Almost no respondents reported consuming these foods more frequently in winter than in summer.

Tables 3 to 5 show the ORs for the development of cancer and CVD separately and for CVD and/or cancer
Table 1 Cancer and CVD morbidity and mortality at HALS2 in subjects free of these diseases at HALS1

\begin{tabular}{lrrrrr}
\hline & \multicolumn{2}{c}{ Men } & & \multicolumn{2}{c}{ Women } \\
\cline { 2 - 3 } \cline { 6 - 7 } & \multicolumn{1}{c}{$n$} & $\%$ & & $n$ & $\%$ \\
\hline No CVD & 1217 & & & 1639 & \\
CVD alive & 122 & 8.6 & & 109 & 6.0 \\
CVD dead & 83 & 5.8 & & 78 & 4.3 \\
No cancer & 1341 & & & 1744 & \\
Cancer alive & 36 & 2.5 & & 70 & 3.7 \\
Cancer dead & 65 & 4.5 & & 61 & 3.3 \\
No CVD or cancer & 1190 & & & 1589 & \\
CVD or cancer alive & 151 & 10.1 & & 172 & 9.1 \\
CVD or cancer dead & 148 & 9.9 & & 139 & 7.3 \\
\hline
\end{tabular}

combined in relation to the frequency of consumption of salad vegetables in winter and summer and fresh fruit in winter and summer, with never eating the food items as the reference categories. In men the ORs for trend show that there was a protective effect against cancer, CVD and cancer and/or CVD of frequently consuming salad vegetables. The relationships were stronger for winter salad vegetable consumption ( $P=0.045$ for cancer, 0.049 for CVD and 0.004 for CVD and/or cancer) than for summer salad consumption ( $P=\mathrm{NS}$ for all three cases). The odds of developing cancer were estimated to be reduced by $21 \%$ per frequency category of increasing winter salad vegetable consumption. The comparable figures for CVD and cancer and/or CVD were 15\% and $19 \%$, respectively. There were no significant associations between the frequencies of fresh fruit consumption in summer or winter and the development of disease.

In women, increasing salad vegetable consumption in winter or in summer was associated with a strong protective effect for CVD $(P<0.001$ for winter and summer salad vegetables) (Table 4) and cancer and/or CVD $(P<0.001$ and $P=0.001$ for winter and summer salad vegetables, respectively) (Table 5). Although the trends were in the same direction for cancer, with the ORs below 1 for the trend and for all consumption categories above the reference category, the trend was not statistically significant at the 5\% level (Table 3). Frequent fresh fruit consumption in winter or summer was also associated with a reduced risk of CVD $(P=0.004$ and 0.014 for winter and summer fresh fruit, respectively: Table 4) and cancer and/or CVD $(P<0.001$ and $P=0.007$ for winter and summer fresh fruit, respectively: Table 5). Winter fresh fruit showed an almost significant protective effect against cancer $(P=0.052)$ (Table 3$)$. The protective effect of frequent fresh food consumption was stronger with salad vegetables for $\mathrm{CVD}$, where the odds of developing CVD were reduced by $24 \%$ per increase of frequency category for winter salad vegetables, compared to $16 \%$ for winter fruit. The comparable figures for cancer and/or CVD were $19 \%$ for winter salad vegetables and 15\% for winter fresh fruit. 
Table 2a Percentage of male respondents $(n=1489)$ in each frequency of consumption group for salad vegetables and fresh fruit by season

\begin{tabular}{|c|c|c|c|c|c|c|c|c|c|c|c|c|c|}
\hline \multirow[b]{2}{*}{ Frequency } & \multicolumn{6}{|c|}{ Salad in summer } & \multirow[b]{2}{*}{ Frequency } & \multicolumn{6}{|c|}{ Fruit in summer } \\
\hline & Never & $<1 /$ week & 1-2/week & Most days & Daily & (Total) & & Never & $<1 /$ week & 1-2/week & Most days & Daily & (Total) \\
\hline Salad in winter & & & & & & & Fruit in winter & & & & & & \\
\hline Never & 5.2 & 2.9 & 10.4 & 3.9 & 1.8 & (24.2) & Never & 5.0 & 1.7 & 1.8 & * & 0.8 & $(9.6)$ \\
\hline$<1 /$ week & $*$ & 3.6 & 14.0 & 12.0 & 2.9 & (32.6) & $<1 /$ week & 0 & 8.1 & 6.8 & 0.7 & 1.7 & (17.4) \\
\hline 1-2/week & $*$ & 0 & 10.0 & 15.2 & 7.1 & (32.4) & 1-2/week & 0 & $*$ & 11.1 & 5.2 & 7.9 & (24.5) \\
\hline Most days & 0 & 0 & * & 4.4 & 2.8 & $(7.3)$ & Most days & 0 & $*$ & $*$ & 6.1 & 7.1 & (13.4) \\
\hline Daily & 0 & 0 & $*$ & $*$ & 3.2 & (3.6) & Daily & 0 & $*$ & $*$ & $*$ & 34.7 & (35.1) \\
\hline (Total) & (5.3) & (6.5) & (34.6) & (35.8) & (17.8) & & (Total) & (5.0) & (10.3) & (20.0) & (12.6) & (52.2) & \\
\hline
\end{tabular}

*Less than $0.5 \%$.

Table $\mathbf{2 b}$ Percentage of female respondents $(n=190)$ in each frequency of consumption group for salad vegetables and fresh fruit by season

\begin{tabular}{|c|c|c|c|c|c|c|c|c|c|c|c|c|c|}
\hline \multirow[b]{2}{*}{ Frequency } & \multicolumn{6}{|c|}{ Salad in summer } & \multirow[b]{2}{*}{ Frequency } & \multicolumn{6}{|c|}{ Fruit in summer } \\
\hline & Never & $<1 /$ week & 1-2/week & Most days & Daily & (Total) & & Never & $<1 /$ week & $1-2 /$ week & Most days & Daily & (Total) \\
\hline Salad in winter & & & & & & & Fruit in winter & & & & & & \\
\hline Never & 2.2 & 1.2 & 6.9 & 4.9 & 2.1 & (17.3) & Never & 2.8 & 1.0 & 0.8 & $*$ & 0.6 & $(5.6)$ \\
\hline$<1 /$ week & 0 & 2.1 & 9.2 & 10.3 & 4.4 & (26.0) & $<1 /$ week & 0 & 4.5 & 3.6 & 0.8 & 2.7 & (11.6) \\
\hline 1-2/week & $*$ & $*$ & 8.1 & 16.5 & 11.9 & (36.7) & $1-2 /$ week & 0 & $*$ & 6.1 & 4.1 & 7.6 & (17.9) \\
\hline Most days & 0 & $*$ & $*$ & 5.6 & 5.9 & (11.8) & Most days & 0 & 0 & $*$ & 5.8 & 8.9 & (15.0) \\
\hline Daily & $\begin{array}{l}0 \\
(23)\end{array}$ & $\begin{array}{l}0 \\
(34)\end{array}$ & $\begin{array}{c}0 \\
(245)\end{array}$ & $\begin{array}{c}* \\
* \\
(376)\end{array}$ & $\begin{array}{c}7.8 \\
32 ?)\end{array}$ & $(8.2)$ & Daily & $\begin{array}{l}0 \\
(28)\end{array}$ & $*$ & $\begin{array}{c}* \\
(108)\end{array}$ & ${ }^{*}$ & $\begin{array}{c}49.5 \\
(69.4)\end{array}$ & (49.9) \\
\hline
\end{tabular}

*Less than $0.5 \%$. 
Table 3 Odds ratios for developing cancer (morbidity or mortality) in 7 years in relation to the seasonal consumption of salad vegetables and fresh fruit (adjusted for age in 5-year bands, smoking and socioeconomic group)

\begin{tabular}{|c|c|c|c|c|c|c|c|c|}
\hline & \multicolumn{2}{|c|}{ Salad in winter } & \multicolumn{2}{|c|}{ Salad in summer } & \multicolumn{2}{|c|}{ Fruit in winter } & \multicolumn{2}{|c|}{ Fruit in summer } \\
\hline & OR & $n$ & OR & $n$ & OR & $n$ & OR & $n$ \\
\hline \multicolumn{9}{|c|}{$\operatorname{Men}(n=1442)$} \\
\hline \multicolumn{9}{|c|}{ Frequency } \\
\hline Never & 1.00 & 337 & 1.00 & 75 & 1.00 & 132 & 1.00 & 68 \\
\hline$<\mathrm{l} /$ week & 0.89 & 470 & 0.93 & 92 & 0.85 & 246 & 1.98 & 145 \\
\hline $1-2 /$ week & 0.65 & 472 & 0.77 & 490 & 0.91 & 358 & 2.03 & 293 \\
\hline Most days & 0.43 & 111 & 0.40 & 524 & 0.98 & 194 & 1.39 & 182 \\
\hline Daily & 0.36 & 52 & 0.70 & 261 & 0.64 & 512 & 1.62 & 754 \\
\hline Trend & 0.79 & & 0.83 & & 0.91 & & 1.00 & \\
\hline $95 \% \mathrm{Cl}$ & $0.62-0.99$ & & $0.69-1.01$ & & $0.78-1.06$ & & $0.85-1.17$ & \\
\hline$P$ & 0.045 & & 0.070 & & 0.230 & & 0.967 & \\
\hline \multicolumn{9}{|c|}{ Women $(n=1875)$} \\
\hline \multicolumn{9}{|c|}{ Frequency } \\
\hline Never & 1.00 & 313 & 1.00 & 36 & 1.00 & 100 & 1.00 & 48 \\
\hline$<1 /$ week & 0.86 & 484 & 0.39 & 62 & 1.42 & 212 & 1.74 & 105 \\
\hline 1-2/week & 0.73 & 695 & 0.54 & 458 & 0.93 & 341 & 1.54 & 205 \\
\hline Most days & 0.98 & 226 & 0.58 & 705 & 0.93 & 282 & 1.49 & 216 \\
\hline Daily & 0.39 & 157 & 0.42 & 614 & 0.75 & 940 & 0.98 & 1301 \\
\hline Trend & 0.88 & & 0.89 & & 0.87 & & 0.88 & \\
\hline $95 \% \mathrm{Cl}$ & $0.75-1.03$ & & $0.74-1.06$ & & $0.76-1.00$ & & $0.75-1.02$ & \\
\hline$P$ & 0.131 & & 0.210 & & 0.052 & & 0.097 & \\
\hline
\end{tabular}

The results so far have demonstrated the separate associations of summer and winter consumption of food items with the incidence of cancer and/or CVD, where the stronger associations were with winter consumption. Table 2 shows that whilst consumption in winter rarely exceeded that in summer for salad vegetables or fresh fruit, it was often lower. Only $3.6 \%$ of men and $8.2 \%$ of women consumed salad vegetables on a daily basis in winter, compared to $17.8 \%$ and $32.2 \%$, respectively, in summer. Conversely, $24.2 \%$ of men and $17.3 \%$ of women never ate salad vegetables in winter, compared to only
$5.3 \%$ and $2.3 \%$, respectively, in summer. Similar trends were seen for fresh fruit consumption, although the proportions not eating fresh fruit in winter were smaller and the proportions eating fresh fruit on a daily basis in summer and winter were higher than for salads at comparable seasons. There were thus a considerable number of respondents whose frequency of consumption, particularly of salad vegetables, was less in winter than summer.

Table 6 presents the results of analysis where respondents who maintained their frequency of salad

Table 4 Odds ratios for developing CVD (morbidity or mortality) in 7 years in relation to the seasonal consumption of salad vegetables and fresh fruit (adjusted for age in 5-year bands, smoking and socioeconomic group)

\begin{tabular}{|c|c|c|c|c|c|c|c|c|}
\hline & \multicolumn{2}{|c|}{ Salad in winter } & \multicolumn{2}{|c|}{ Salad in summer } & \multicolumn{2}{|c|}{ Fruit in winter } & \multicolumn{2}{|c|}{ Fruit in summer } \\
\hline & OR & $n$ & OR & $n$ & OR & $n$ & OR & $n$ \\
\hline \multicolumn{9}{|c|}{$\operatorname{Men}(n=1422)$} \\
\hline \multicolumn{9}{|c|}{ Frequency } \\
\hline Never & 1.00 & 333 & 1.00 & 70 & 1.00 & 131 & 1.00 & 70 \\
\hline$<\mathrm{l} /$ week & 0.80 & 465 & 0.72 & 90 & 0.54 & 248 & 0.54 & 144 \\
\hline $1-2 /$ week & 0.74 & 464 & 0.86 & 490 & 0.72 & 346 & 0.77 & 281 \\
\hline Most days & 0.42 & 108 & 0.82 & 519 & 0.83 & 192 & 0.67 & 180 \\
\hline Daily & 0.66 & 52 & 0.72 & 253 & 0.69 & 505 & 0.81 & 747 \\
\hline Trend & 0.85 & & 0.95 & & 0.98 & & 1.03 & \\
\hline $95 \% \mathrm{Cl}$ & $0.72-1.00$ & & $0.82-1.10$ & & $0.87-1.09$ & & $0.91-1.16$ & \\
\hline$P$ & 0.049 & & 0.522 & & 0.705 & & 0.634 & \\
\hline \multicolumn{9}{|c|}{ Women $(n=1826)$} \\
\hline \multicolumn{9}{|c|}{ Frequency } \\
\hline Never & 1.00 & 305 & 1.00 & 38 & 1.00 & 98 & 1.00 & 51 \\
\hline$<1 /$ week & 0.72 & 474 & 0.59 & 63 & 0.95 & 207 & 0.39 & 99 \\
\hline 1-2/week & 0.67 & 676 & 0.36 & 447 & 0.75 & 327 & 0.85 & 197 \\
\hline Most days & 0.31 & 219 & 0.32 & 683 & 0.69 & 275 & 0.57 & 204 \\
\hline Daily & 0.35 & 152 & 0.26 & 595 & 0.52 & 919 & 0.43 & 1275 \\
\hline Trend & 0.76 & & 0.76 & & 0.84 & & 0.85 & \\
\hline $95 \% \mathrm{Cl}$ & $0.65-0.89$ & & $0.65-0.89$ & & $0.74-0.94$ & & $0.74-0.97$ & \\
\hline$P$ & $<0.001$ & & $<0.001$ & & 0.004 & & 0.014 & \\
\hline
\end{tabular}


Table 5 Odds ratios for developing disease (cancer and/or CVD morbidity or mortality) in relation to the seasonal consumption of salad vegetables and fresh fruit (adjusted for age in 5-year bands, smoking and socioeconomic group)

\begin{tabular}{|c|c|c|c|c|c|c|c|c|}
\hline & \multicolumn{2}{|c|}{ Salad in winter } & \multicolumn{2}{|c|}{ Salad in summer } & \multicolumn{2}{|c|}{ Fruit in winter } & \multicolumn{2}{|c|}{ Fruit in summer } \\
\hline & OR & $n$ & OR & $n$ & OR & $n$ & OR & $n$ \\
\hline \multicolumn{9}{|c|}{ Men $(n=1489)$} \\
\hline \multicolumn{9}{|c|}{ Frequency } \\
\hline Never & 1.00 & 360 & 1.00 & 79 & 1.00 & 143 & 1.00 & 74 \\
\hline$<\mathrm{l} /$ week & 0.76 & 485 & 0.84 & 97 & 0.62 & 259 & 0.79 & 153 \\
\hline 1-2/week & 0.67 & 482 & 0.81 & 515 & 0.76 & 365 & 0.98 & 298 \\
\hline Most days & 0.41 & 109 & 0.64 & 533 & 0.83 & 200 & 0.79 & 187 \\
\hline Daily & 0.51 & 53 & 0.67 & 265 & 0.67 & 522 & 0.94 & 777 \\
\hline Trend & 0.81 & & 0.89 & & 0.96 & & 1.01 & \\
\hline $95 \% \mathrm{Cl}$ & $0.70-0.94$ & & $0.78-1.02$ & & $0.86-1.06$ & & $0.91-1.13$ & \\
\hline$P$ & 0.004 & & 0.095 & & 0.387 & & 0.843 & \\
\hline \multicolumn{9}{|c|}{ Women $(n=1900)$} \\
\hline \multicolumn{9}{|c|}{ Frequency } \\
\hline Never & 1.00 & 329 & 1.00 & 43 & 1.00 & 106 & 1.00 & 54 \\
\hline$<1 /$ week & 0.77 & 494 & 0.52 & 65 & 1.19 & 221 & 0.71 & 108 \\
\hline 1-2/week & 0.70 & 697 & 0.42 & 465 & 0.85 & 340 & 1.04 & 206 \\
\hline Most days & 0.51 & 225 & 0.40 & 715 & 0.75 & 285 & 0.86 & 214 \\
\hline Daily & 0.38 & 155 & 0.30 & 612 & 0.61 & 948 & 0.58 & 1318 \\
\hline Trend & 0.81 & & 0.81 & & 0.85 & & 0.86 & \\
\hline $95 \% \mathrm{Cl}$ & $0.71-0.91$ & & $0.71-0.92$ & & $0.77-0.93$ & & $0.77-0.96$ & \\
\hline$P$ & $<0.001$ & & 0.001 & & $<0.001$ & & 0.007 & \\
\hline
\end{tabular}

vegetable consumption from summer to winter, approximately $60 \%$ of men and women, were compared with those with the same summer consumption but whose consumption was reduced in winter by at least two frequency categories, $38.1 \%$ of men and $40.5 \%$ of women. The ORs show the higher risk for cancer and cancer and/ or CVD in men and CVD in women, in those whose frequency of salad vegetable consumption was reduced in winter compared to those whose frequency of consumption was maintained. Reduction of salad vegetable consumption in winter was significantly associated with a $64 \%$ increase in cancer odds in men and a $47 \%$ increase in CVD odds for women when compared with seasonal maintenance.

For fresh fruit, fewer respondents reduced their frequency of consumption by two or more frequency categories between summer and winter, with approximately $80 \%$ of men and $82 \%$ of women maintaining their summer level of consumption through the winter. The findings for fresh fruit consumption (not shown) revealed that although all the ORs were above 1, indicating a greater risk of disease development for those who reduced their frequency of intake in winter, the increases were not statistically significant. The lack of significance may relate to the small numbers in all but the 'reduced' consumption groups who were daily consumers in summer.

Table 7 shows the effects of smoking before and after adjusting for winter salad vegetable consumption in relation to cancer, CVD and cancer and/or CVD development. For men, heavy and light smoking were both associated with the development of cancer and cancer and/or CVD (odds almost twice, or more, those of nonsmokers) and these associations, although somewhat attenuated when adjusted for winter salad vegetable consumption, were still significant $(P=0.035$ for cancer and $P=0.008$ for cancer and/or CVD). Current smoking was not significantly associated with an increased risk of developing CVD and on adjusting for winter salad vegetable consumption the tendency was further reduced. For women, only heavy smoking was significantly associated with an increased risk of developing cancer and cancer and/or CVD, and the significance of this association was maintained, although the ORs were somewhat reduced when adjusted for winter salad vegetables $(P=0.029$ for cancer and $P=0.022$ for cancer and/or CVD). As with the men, there was no significant association between heavy smoking and CVD, either before or after adjusting for winter salad vegetables. The ex-smokers did not differ from the non-smokers in relation to the development of disease, whether or not adjusted for winter salad. The overall smoking effect was attenuated, but remained significant, when adjustment was made for winter salad vegetables for cancer and cancer and/or CVD for both men $(P=0.035$ and $P=0.008$ respectively) and women $(P=0.029$ and $P=0.022)$.

The independent effects of socioeconomic group are shown in Table 8. Manual men had an increased risk of developing cancer $(P=0.046)$, but this became nonsignificant when winter salad vegetables were adjusted for $(P=0.108)$. Similar, but less close, trends were seen for women. For CVD the associations with socioeconomic group (adjusted for just age and smoking) were much closer for women $(P<0.001)$ than for men $(P=0.010)$. When winter salad vegetables were included, the relationships were attenuated but remained significant for men $(P=0.029)$ and women $(P=0.006)$.

Once social class, smoking and seasonal food consumption were adjusted for, region of residence (northern England, southern England, Wales and Scotland) was not 
Table 6 Seasonal salad vegetable consumption and odds of developing cancer, CVD or disease (cancer and/or CVD) morbidity or mortality in 7 years in relation to maintained* or reduced $\dagger$ frequency of consumption in winter (adjusted for age in 5-year bands, smoking and socioeconomic group)

\begin{tabular}{|c|c|c|c|c|c|c|c|c|c|c|c|}
\hline & \multicolumn{3}{|c|}{ Cancer } & \multicolumn{4}{|c|}{ CVD } & \multicolumn{4}{|c|}{ CVD/cancer } \\
\hline & Maintained WF & \multicolumn{2}{|c|}{ Reduced WF } & \multicolumn{2}{|c|}{ Maintained WF } & \multicolumn{2}{|c|}{ Reduced WF } & \multicolumn{2}{|c|}{ Maintained WF } & \multicolumn{2}{|c|}{ Reduced WF } \\
\hline & OR & OR & $n$ & OR & $n$ & OR & $n$ & OR & $n$ & OR & $n$ \\
\hline \multicolumn{12}{|c|}{ Men } \\
\hline \multicolumn{12}{|c|}{ Summer salad frequency } \\
\hline Never & 1.00 & & & 1.00 & 70 & & & 1.00 & 79 & & \\
\hline$<\mathrm{l} /$ week & 0.92 & & & 0.71 & 90 & & & 0.83 & 97 & & \\
\hline $1-2 /$ week & 0.69 & 0.87 & 146 & 0.86 & 346 & 0.88 & 144 & 0.75 & 360 & 0.89 & 155 \\
\hline Most days & 0.26 & 0.54 & 225 & 0.54 & 291 & 1.16 & 228 & 0.42 & 296 & 0.88 & 237 \\
\hline Daily & 0.28 & 0.84 & 177 & 0.71 & 83 & 0.71 & 170 & 0.55 & 84 & 0.71 & 181 \\
\hline \multicolumn{12}{|c|}{ Increase in risk by reduction } \\
\hline OR $(95 \% \mathrm{Cl})$ & $1.64(1.00-2.68)$ & & & $1.38(0$ & 97) & & & $1.52(1$ & 09) & & \\
\hline$P$ & $0.050 \quad 1422$ & & & 0.076 & 1422 & & & 0.010 & 1489 & & \\
\hline \multicolumn{12}{|c|}{ Women } \\
\hline \multicolumn{12}{|c|}{ Summer salad frequency } \\
\hline Never & 1.00 & & & 1.00 & 39 & & & 1.00 & 43 & & \\
\hline$<\mathrm{l} /$ week & 0.40 & & & 0.59 & 64 & & & 0.51 & 65 & & \\
\hline $1-2 /$ week & 0.57 & 0.49 & 127 & 0.35 & 325 & 0.38 & 125 & 0.41 & 334 & 0.42 & 131 \\
\hline Most days & 0.58 & 0.58 & 281 & 0.27 & 414 & 0.40 & 273 & 0.37 & 426 & 0.43 & 289 \\
\hline Daily & 0.40 & 0.44 & 366 & 0.15 & 241 & 0.32 & 358 & 0.22 & 246 & 0.36 & 366 \\
\hline \multicolumn{12}{|c|}{ Increase in risk by reduction } \\
\hline OR $(95 \% \mathrm{Cl})$ & $1.02(0.69-1.50)$ & & & $1.47(1$ & 04) & & & $1.23(0$ & 63) & & \\
\hline$P$ & $0.940 \quad 1875$ & & & 0.024 & 1826 & & & 0.146 & 1900 & & \\
\hline
\end{tabular}

WF, winter frequency.

The same or one frequency category lower in winter.

Two or more frequency categories lower in winter. 
Table 7 Odds ratios for the development of cancer, CVD and disease (cancer and/or CVD morbidity or mortality) in relation to smoking (adjusted for age and social group or age, social group and winter salad vegetable consumption)

\begin{tabular}{|c|c|c|c|c|c|c|c|c|c|c|c|c|c|c|}
\hline & \multicolumn{7}{|c|}{ Men } & \multicolumn{6}{|c|}{ Women } & \\
\hline & \multicolumn{3}{|c|}{$\begin{array}{l}\text { Age and social group } \\
\text { adjusted }\end{array}$} & \multicolumn{3}{|c|}{$\begin{array}{l}\text { Age, social group and } \\
\text { winter salad adjusted }\end{array}$} & \multirow[b]{2}{*}{$n$} & \multicolumn{3}{|c|}{$\begin{array}{l}\text { Age and social group } \\
\text { adjusted }\end{array}$} & \multicolumn{3}{|c|}{$\begin{array}{l}\text { Age, social group and } \\
\text { winter salad adjusted }\end{array}$} & \multirow[b]{2}{*}{$n$} \\
\hline & OR & $95 \% \mathrm{Cl}$ & $P$ & OR & $95 \% \mathrm{Cl}$ & $P$ & & OR & $95 \% \mathrm{Cl}$ & $P$ & OR & $95 \% \mathrm{Cl}$ & $P$ & \\
\hline \multicolumn{15}{|l|}{ Cancer } \\
\hline Non-smoker & 1.00 & - & - & 1.00 & - & - & 361 & 1.00 & - & - & 1.00 & - & - & 841 \\
\hline Light & 2.44 & $1.16-5.37$ & 0.026 & 2.26 & $1.02-4.97$ & 0.044 & 277 & 1.10 & $0.66-1.83$ & 0.712 & 1.07 & $0.64-1.78$ & 0.794 & 338 \\
\hline Heavy & 3.15 & $1.44-6.88$ & 0.004 & 2.72 & $1.23-6.01$ & 0.013 & 287 & 2.08 & $1.26-3.42$ & 0.004 & 1.97 & $1.19-3.25$ & 0.009 & 245 \\
\hline Ex-smoker & 1.61 & $0.76-3.38$ & 0.211 & 1.51 & $0.72-3.20$ & 0.277 & 517 & 0.84 & $0.51-1.38$ & 0.484 & 0.84 & $0.51-1.38$ & 0.481 & 464 \\
\hline Smoking effect* & 11.45 & & 0.010 & 8.63 & & 0.035 & & 10.45 & & 0.015 & 9.05 & & 0.029 & \\
\hline \multicolumn{15}{|l|}{$\begin{array}{l}C V D \\
\text { Smoking status }\end{array}$} \\
\hline Non-smoker & 1.00 & - & - & 1.00 & - & - & 358 & 1.00 & - & - & 1.00 & - & - & 817 \\
\hline Light & 1.59 & $0.97-2.61$ & 0.067 & 1.51 & $0.99-2.66$ & 0.105 & 272 & 1.35 & $0.87-2.07$ & 0.181 & 1.27 & $0.87-2.08$ & 0.279 & 329 \\
\hline Heavy & 1.51 & $0.91-2.51$ & 0.114 & 1.36 & $0.92-2.57$ & 0.246 & 274 & 1.50 & $0.90-2.50$ & 0.118 & 1.33 & $0.88-2.45$ & 0.278 & 233 \\
\hline Ex-smoker & 1.02 & $0.65-1.61$ & 0.928 & 0.99 & $0.69-1.70$ & 0.955 & 518 & 0.79 & $0.51-1.21$ & 0.273 & 0.78 & $0.51-1.22$ & 0.255 & 447 \\
\hline Smoking effect* & 6.75 & & 0.080 & 5.23 & & 0.156 & & 6.82 & & 0.078 & 4.95 & & 0.175 & \\
\hline \multirow{2}{*}{\multicolumn{15}{|c|}{$\begin{array}{l}\text { Disease (cancer and/or CVD) } \\
\text { Smoking status }\end{array}$}} \\
\hline Non-smoker & 1.00 & - & & & & & & & & & & & & \\
\hline Light & 194 & $124-305$ & ang & 1.00 & - & - & 364 & 1.00 & - & - & 1.00 & - & - & $\begin{array}{l}843 \\
346\end{array}$ \\
\hline Heavy & 200 & $127-316$ & 0.003 & 1.84 & $1.17-2.90$ & 0.009 & 289 & 1.22 & $0.85-1.74$ & 0.276 & 1.16 & $0.81-1.65$ & 0.418 & $\begin{array}{l}346 \\
251\end{array}$ \\
\hline Ex-smoker & 2.00 & & 0.003 & 1.77 & $1.11-2.82$ & 0.016 & 296 & 1.75 & $1.19-2.57$ & 0.004 & 1.59 & $1.08-2.35$ & 0.020 & 251 \\
\hline Smoking effect* & 1.20 & $0.19-1.02$ & 0.384 & 1.15 & $0.76-1.75$ & 0.500 & 540 & 0.81 & $0.58-1.15$ & 0.240 & 0.81 & $0.57-1.14$ & 0.230 & 460 \\
\hline & 15.42 & & 0.001 & 11.16 & & & & 13.01 & & 0.005 & & & 0.022 & \\
\hline
\end{tabular}

*Chi-square distribution with 3 degrees of freedom. 


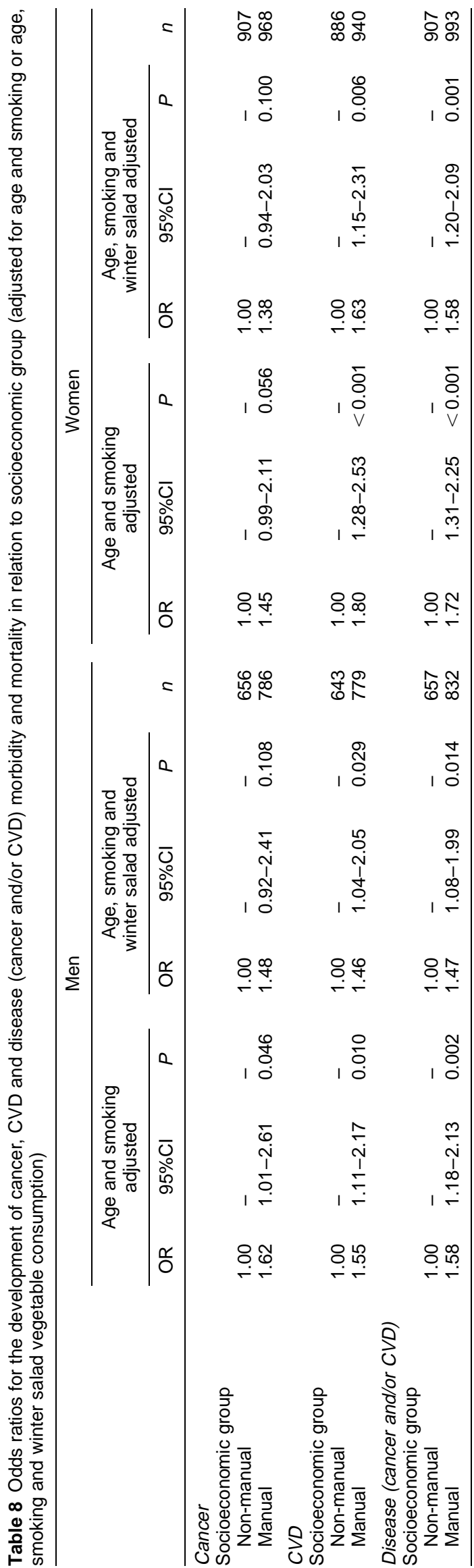

associated with the development of cancer, CVD or cancer and/or CVD.

\section{Discussion}

The present study confirms preliminary findings of an association of year-round salad/raw vegetable consumption with a reduced risk of developing cancer in $\operatorname{men}^{10}$ and of year-round fresh fruit consumption with a low risk of $\mathrm{CVD}^{9}$, at least for women. Despite the relatively short period of follow-up (7 years) and relatively small sample compared to many studies, the consistency of the trends in relation to the frequency of consumption of seasonal foods and the risk of developing diseases, which are the major causes of mortality in developed countries, add weight to the argument favouring the importance of these foods in maintaining health. As far as we are aware the Health and Lifestyle Survey was unique in collecting data on the summer and winter consumption of seasonal foods and in comparing the protective effect of this seasonal consumption.

The differing patterns of winter and summer frequency of consumption, particularly for salad vegetables, fit in well with the findings of the differences in the amounts of salad vegetables and fresh fruit purchased in summer and winter reported by the National Food Survey ${ }^{3}$. This indicates that, although portion sizes were not measured and the amounts consumed were likely to have differed widely between the respondents, the frequencies of consumption recorded here did broadly reflect the amount of food consumed.

The frequent ('Most days' or 'Daily') winter consumption of fresh fruit and salad or raw vegetables reflected year-round frequent consumption, since almost no respondents reported consuming these foods more frequently in winter than summer. Since many of those who reported frequent summer consumption, particularly of salad vegetables, were infrequent winter consumers, the group of frequent summer consumers was a mixture of frequent all-year-round consumers - with the least risk of developing CVD and/or cancer - and summer frequent/ winter infrequent consumers, who whilst not at so great a risk of developing disease are not so well protected as the habitual consumers ${ }^{9}$. This is shown in Table 6, where those who maintained their level of consumption were compared with those who ate salad vegetables less frequently in winter than in summer. The differences between the pattern of summer and winter (year-round) consumption were greater for salad vegetables than for fresh fruit, and since frequent winter salad vegetable consumption was found to be more closely associated with a protective effect for CVD and, in men, cancer, the benefits of changing dietary habits to include salads or raw vegetables in the menu throughout the year need to be emphasized in public health messages. These need to be targeted particularly at those who through upbringing or 
habit do not eat seasonal fresh foods regularly, especially now that these are more readily available year round.

It has been stated above that as it was not feasible to measure portion sizes no quantitative assessment of food consumption could be made, and neither therefore could an assessment be made of nutrient intake. Furthermore as the respondents were questioned about broad categories of fresh fruit and salad vegetables, rather than individual items, there is little indication of exactly which foods or micronutrients might be involved in the risk reduction process. Overall there is more evidence to suggest that fresh fruit and vegetables are protective against $\mathrm{CVD}^{13}$ and cancer $^{14}$, with the majority of studies relating fruit or vegetable consumption and cancer showing a positive protective effect $(78 \%)^{2}$, than any one or combination of antioxidant vitamins. Intervention studies where vitamin supplements have been given have almost always been unsuccessful in lowering the incidence of these diseases ${ }^{15-18}$. Part of the lack of consistency with regard to the studies attempting to relate antioxidant vitamins to the risk of CVD or cancer may lie in the seasonal variation in intake and blood levels associated with seasonal consumption of the host foods. It may also be that antioxidants act synergistically as suggested by Diplock and Rogers ${ }^{19}$ or that other factors present in fresh produce, such as flavenoids, may be important ${ }^{20}$. As far as cancer is concerned, a study of men in the USA has found that a high intake of tomatoes and lycopene, the carotene found principally in tomatoes, were protective against prostate cancer ${ }^{21}$. There were no significant associations between other vegetables or the other carotenes measured, including $\beta$-carotene, and cancer risk. Since tomatoes are a major constituent of most salad dishes, the effects observed in the present study could be associated with the lycopene in tomatoes, and it is possible that had seasonality been taken into account in the prostate cancer study the significance of the associations between tomatoes and lycopene with cancer development $-P=$ 0.03 and $P=0.04$, respectively - might have been closer. Whatever the mechanisms underlying the effects of habitual salad vegetable and also habitual fresh fruit consumption observed in this study, the findings are supported by the fact that the majority of studies relating fruit or vegetable consumption and cancer have shown a positive protective effect ${ }^{2}$.

Although it appears that salad and raw vegetables and fresh fruit are associated with a reduced risk of the two major causes of mortality, could it be that these items are merely reflecting an overall healthy lifestyle or diet? Previous studies of the Health and Lifestyle Survey data using principal component analysis have revealed four main dietary patterns, the major one (component 1) of which is weighted positively for foods considered 'healthy' - salads, fresh fruits, juice, 'brown' bread, vegetables, breakfast cereals and low-fat foods (semi- and skimmed milk and low-fat spreads) - and negatively for fatty and fried foods ${ }^{22}$.
Indeed salad vegetables and fresh fruit had the highest positive weightings; that is they were the most important foods in component 1 . This diet was also associated with not smoking, moderate alcohol consumption, a sense of well-being and reporting few symptoms of illness. Frequent salad vegetable and fresh fruit consumption is mirrored by the infrequent consumption of many high-fat foods, so that frequent fresh food consumers are unlikely to be also frequent consumers of high-fat foods. Identifying protective or detrimental components of the diet is always difficult and complex, and the by no means universal findings of positive associations between a highfat diet and increased incidence of disease, may actually be reflecting a reduced protection due to inadequate fresh produce consumption. This suggestion is supported by the finding that the results shown in Tables 2-4 were materially unaffected by adjusting for component 1 .

Smoking, as has been clearly established in many studies, is a major risk factor for cancer development, whereas the present findings suggest that socioeconomic status, once dietary factors associated with it have been allowed for, is of much less significance. On the other hand, the association of socioeconomic group rather than smoking with CVD is in accord with the findings of Marmot et al. ${ }^{23}$ in the Whitehall study who found that men who had little control over their jobs were more likely to be of lower social class and suffered more CVD. Furthermore, deprivation in early life ${ }^{24}$ can predispose towards CVD. This might also apply to the women, where the independent risk of CVD for manual women was 63\% higher than for non-manual women.

The stronger association for men than women between salad vegetable consumption and cancer may be related to the different pattern of cancer development in the two sexes in Great Britain ${ }^{14}$. Mortality rates are higher in men for cancers of the stomach, intestinal tract and lung, for which there is stronger evidence of a protective effect of fruit and vegetables, than for cancer of the breast which is a major cause of cancer mortality in women ${ }^{25}$. The relatively small numbers in the present study did not permit differential analysis by cancer site. Similarly with CVD it was not possible to analyse separately myocardial infarctions, angina and stroke. However, since there is evidence that low rates of both coronary heart disease ${ }^{26}$ and stroke $^{27}$ are associated with fruit and vegetable consumption, these distinctions need not be made.

The attenuation of the relative risk for smoking, particularly in relation to CVD, by adjusting for seasonal foods (notably winter salad vegetable consumption) suggested that part of the risk usually associated with smoking was due to a lack of consumption of protective foods. It has previously been shown that subjects who frequently consumed fresh fruit in winter and/or fruit juice had better lung function $\left(\mathrm{FEV}_{1}\right)$ than infrequent fruit and/ or fruit juice consumers of the same age, stature and smoking status ${ }^{7}$. Thus frequent fresh fruit consumption to 
some extent may counteract the deleterious effects of smoking on lung function. Furthermore, smokers have been found to consume less fresh fruit and salad vegetables, even when social class was taken into account ${ }^{28}$.

\section{Conclusion}

The stronger protective effects of habitual (summer and winter) consumption of fresh produce, compared to summer-only frequent consumption, in protecting against cancer and CVD highlights the importance of discriminating between the seasons in the consumption of fresh fruit and salad vegetables.

\section{Acknowledgements}

This study was supported by a grant from the Anglia and Oxford Regional Health Authority.

\section{References}

1 Ness A, Powles JW. Fruit and vegetables, and cardiovascular disease: a review. Int. J. Epidemiol. 1996; 26: 1-13.

2 World Cancer Research Fund. Food Nutrition and the Prevention of Cancer: a Global Perspective. Washington: American Institute for Cancer Research, 1997; 442.

3 National Food Survey Committee. Household Food Consumption and Expenditure: 1985. London: HMSO, 1987; 61-2.

4 Cox BD, Blaxter M, Buckle ALJ, et al. The Health and Lifestyle Survey. London: Health Promotion Research Trust, 1987.

5 Cox BD, Huppert FA, Whichelow MJ, eds. The Health and Lifestyle Survey: Seven Years On. Aldershot: Dartmouth Publishing Co Ltd, 1993.

6 Powles JW, Day NE, Sanz MA, Bingham SA. Protective foods in winter and spring: a key to lower vascular mortality? Lancet 1996; 348: 898-9.

7 Strachan DP, Cox BD, Erzinclioglu SW, Walters DE, Whichelow MJ. Ventilatory function and winter fresh fruit consumption in a random sample of British adults. Thorax 1991; 46: 624-9.

8 Whichelow MJ, Treasure FP. Diet and health in a random sample of British adults. Proc. Nutr. Soc. 1990; 49: 57A.

9 Cox BD, Whichelow MJ. Seasonal fruit consumption in relation to the development of, or death from, cardiovascular disease. Proc. Nutr. Soc. 1998; 57: 61A.

10 Cox BD, Whichelow MJ. Frequent consumption of red meat is not a risk factor for cancer. BMJ 1997; 315: 1018.

11 Blaxter M. Sample and data collection. In: Cox BD, Blaxter M, Buckle ALJ, et al. The Health and Lifestyle Survey. London: Health Promotion Research Trust, 1987; $1-3$.

12 Whichelow MJ. Dietary habits. In: Cox BD, Blaxter M,
Buckle ALJ, et al. The Health and Lifestyle Survey. London: Health Promotion Research Trust, 1987; 67-84.

13 Rogers L, Sharp I, eds. National Heart Forum. Preventing Coronary Heart Disease: The Role of Antioxidants, Vegetables and Fruit. London: HMSO, 1997; 3.

14 Department of Health. Nutritional Aspects of the Development of Cancer. Report on Health and Social Subjects No. 48. London: HMSO, 1998; 27.

15 Alpha-Tocopherol, Beta-Carotene Cancer Prevention Study Group. The effect of vitamin $\mathrm{E}$ and beta carotene on the incidence of lung cancer and other cancers in male smokers. N. Engl. J. Med. 1994; 330: 1029-35.

16 Hennekens CH, Buring JE, Manson JE, et al. Lack of effect of long-term supplementation with beta-carotene on the incidence of malignant neoplasms and cardiovascular disease. N. Engl. J. Med. 1996; 334: 1145-9.

17 Omenn GS, Goodman GE, Thornquist MD, et al. Effects of a combination of beta-carotene and vitamin A on lung cancer and cardiovascular disease. N. Engl. J. Med. 1996; 334: $1150-5$.

18 Stephens NG, Parsons A, Schofield PM, Kelly F, Cheeseman $\mathrm{K}$, Mitchinson MJ. Randomised controlled trial of vitamin $\mathrm{E}$ in patients with coronary disease: Cambridge Heart Antioxidant Study (CHAOS). Lancet 1996; 347: 781-6.

19 Diplock AT, Rogers LA. Antioxidants and the development of coronary heart disease: the biological basis. In: Rogers L, Sharp I, eds. The National Heart Forum. Preventing Coronary Heart Disease: The Role of Antioxidants, Vegetables and Fruit. London: HMSO, 1997; 11-16.

20 Knekt P, Jarvinen R, Reunanen A, Maatela J. Flavenoid intake and coronary mortality in Finland: a cohort study. BMJ 1996; 312: $478-81$.

21 Giovannucci E, Ascherio A, Rimm EB, Stampfer MJ, Colditz GA, Willett WC. Intake of carotenoids and retinol in relation to risk of prostate cancer. J. Nat. Cancer Inst. 1995; 87: $1767-76$.

22 Whichelow MJ, Prevost AT. Dietary patterns and their associations with demographic, lifestyle and health variables in a random sample of British adults. Br. J. Nutr. 1996; 76 $17-30$.

23 Marmot MG, Bosma H, Hemingway H, Brunner E, Stansfield S. Contribution of job control and other risk factors to social variations in coronary risk incidence. Lancet 1997; 350: 235-9.

24 Barker DJP. The foetal origins of inequalities in health in Britain. J. Public Health Med. 1991; 13: 64-8.

25 World Cancer Research Fund. Food Nutrition and the Prevention of Cancer: A Global Perspective. Washington: American Institute for Cancer Research, 1997; 37.

26 Gaziano JM, Manson JE, Branch LG, Colditz GA, Willett WC, Buring JE. A prospective study of consumption of carotenoids in fruits and vegetables and decreased cardiovascular mortality in the elderly. Ann. Epidemiol. 1995; 5 $255-60$

27 Gilman MW, Cupples LA, Gagnon D, et al. Protective effect of fruits and vegetables on development of stroke in men. JAMA 1995; 273: 1113-17.

28 Whichelow MJ, Erzinclioglu SW, Cox BD. A comparison of the diets of non-smokers and smokers. Br. J. Addict. 1991; 86: $71-81$. 